\title{
Persistence of antibody after accelerated immunisation with diphtheria/tetanus/pertussis vaccine
}

\author{
Mary E B Ramsay, M J Corbel, Keith Redhead, L A E Ashworth, Norman T Begg
}

\begin{abstract}
Objective-To determine the persistence of antibody to diphtheria, tetanus, and pertussis in children receiving an accelerated schedule of primary immunisation.

Design-Controlled study of antibody testing of blood samples from children immunised according to various schedules: three doses of triple vaccine completed at 8-13 calendar months, 6-7 calendar months, before 6 calendar months, or three doses followed by diphtheria/tetanus before age 2 .

Setting-Plymouth Health Authority.

Subjects-129 children aged 4 years who had received three doses of diphtheria/tetanus/pertussis vaccine with or without a diphtheria/tetanus booster.

Main outcome measures-Diphtheria and tetanus antitoxin concentrations and antibody titres to pertussis toxin, filamentous haemagglutinin, and agglutinogens 2 and 3.
\end{abstract}

Results-All children had protective concentrations of antitoxin to diphtheria and tetanus $(\geqslant 0.01 \mathrm{IU} / \mathrm{ml})$. There was no evidence of a significant difference in diphtheria or tetanus antitoxin concentrations and pertussis antibody titres in children immunised with an accelerated course (third dose of triple vaccine before 6 months) compared with those who received a longer course (third dose at 8-13 months) with no booster (geometric mean antitoxin concentration 0.411 (95\% confidence interval 0.273 to 0.618$) v 0.426(0.294$ to 0.616$)$ for diphtheria and $0.358(0.231$ to 0.556$) v 0.299(0.197$ to 0.453$)$ for tetanus; geometric mean antibody titres 903 (500 to $1631) v 1386$ (848 to 2266) for pertussis filamentous haemagglutinin, 179 (130 to 248 ) $v 232$ (167 to 322 ) for pertussis toxin, and 2002 (1276 to 3142$) v 3591$ (2220 to 5809) for agglutinogens 2 and 3 ).

Conclusion-Immunisation with three doses of triple vaccine at monthly intervals completed before 6 months of age probably provides adequate protection against diphtheria, tetanus, and whooping cough which will persist until the age of the preschool booster.

\section{Introduction}

In May 1990 the Department of Health introduced an accelerated schedule of primary immunisation. The ages at which children receive combined diphtheria/ tetanus/pertussis vaccine (triple vaccine) and oral polio vaccine were changed from $3,4-5 \frac{1}{2}$, and $81 / 2-11$ months ${ }^{12}$ to 2,3 , and 4 months. ${ }^{3}$ No further doses are recommended until the diphtheria/tetanus and polio booster at $4 \frac{1}{2} 2-5$ years of age.

There is evidence that accelerated immunisation provides an adequate immediate immune response, ${ }^{4-7}$ but concern has been raised about the persistence of such immunity. ${ }^{8}$ For this reason when an accelerated schedule was recommended during periods of high incidence of whooping cough it was followed by a reinforcing dose of diphtheria/tetanus and polio vaccines at 12-18 months of age. ${ }^{2}$

Plymouth Health Authority employed an accelerated schedule of triple vaccine given at 3,4 , and 5 months followed by a diphtheria/tetanus booster at 18 months of age between January 1985 and May 1987. Many children, however, failed to attend for the scheduled booster dose, and some practitioners chose not to adopt the accelerated course. This provided an opportunity to study the persistence of antibody to diphtheria, tetanus, and pertussis in children who had received different primary immunisation schedules.

\section{Subjects and methods}

Recruitment-In April 1989 children who had received a course of three doses of triple vaccine with or without a diphtheria/tetanus booster were identified by means of the child health computer. Lists of these children with birth dates between 1 March 1985 and 31 December 1985 were sent to 59 participating general practitioners, who then wrote to parents inviting them to take part in the study. If parental consent was obtained appointments were sent to attend for blood sampling at a nearby clinic during June and September 1989. Lignocaine for surface anaesthesia was applied to a suitable venepuncture site and the children returned after one hour, when a sample of venous blood was taken.

Laboratory methods-Serum samples were tested as previously described for diphtheria and tetanus antitoxin concentrations by enzyme linked immunosorbent assay (ELISA) ${ }^{910}$ at the National Institute for Biological Standards and Control and for IgG antibodies to pertussis toxin, filamentous haemagglutinin, and agglutinogens 2 and 3 by ELISA at the ON Public Health Laboratory Service Centre for Applied Microbiology and Research."

Statistical analysis-Children were grouped accord- N ing to the number of doses of vaccine received and the age at which they completed their immunisations with respect to each antigen. Results from children with history of whooping cough were excluded from the analysis of pertussis antibody titres. Mean logarithmic on antitoxin concentrations to diphtheria and tetanus and mean logarithmic antibody titres to each pertussis antigen were compared between the groups with Student's $t$ test. The results from children who had $\mathbb{D}$ received only three doses of diphtheria, tetanus, or pertussis were combined to perform a linear regression of logarithmic antitoxin concentrations or logarithmic antibody titres on age at third dose.

\section{Results}

No child had a diphtheria or tetanus antitoxin concentration below the minimum required for

Dr Begg. 
TABLE I-Distribution of diphtheria and tetanus antitoxin concentrations in 129 children aged 4 years after different immunisation schedules. Figures are numbers (percentages)

\begin{tabular}{|c|c|c|c|c|}
\hline \multirow[b]{3}{*}{ Schedule } & \multicolumn{4}{|c|}{ Antitoxin concentration (IU/ml) } \\
\hline & \multicolumn{2}{|c|}{ Diphtheria } & \multicolumn{2}{|c|}{ Tetanus } \\
\hline & $<0 \cdot 10$ & $\geqslant 0 \cdot 10$ & $<0 \cdot 10$ & $\geqslant 0 \cdot 10$ \\
\hline $\begin{array}{l}\text { Three doses of triple vaccine completed at } 8-13 \\
\text { calendar months }{ }^{\star}(n=35)\end{array}$ & $5(14)$ & $29(83)$ & $4(11)$ & $30(86)$ \\
\hline $\begin{array}{l}\text { Three doses of triple vaccine completed at 6-7 } \\
\text { calendar months }+(n=32)\end{array}$ & $4(13)$ & $28(88)$ & $2(6)$ & $29(90)$ \\
\hline $\begin{array}{l}\text { Three doses of triple vaccine completed before } 6 \\
\text { calendar months }(n=26)\end{array}$ & $2(8)$ & $24(96)$ & $3(12)$ & $23(88)$ \\
\hline $\begin{array}{l}\text { Three doses of triple vaccine followed by diphtheria/ } \\
\text { tetanus before } 2 \text { years of age }(n=36)\end{array}$ & $0(0)$ & $36(100)$ & $0(0)$ & $36(100)$ \\
\hline
\end{tabular}

$\star^{\star}$ One sample $<0 \cdot 25 \mathrm{IU} / \mathrm{ml}$ (diphtheria) and $<0 \cdot 13 \mathrm{IU} / \mathrm{ml}$ (tetanus).

tOne sample $<0 \cdot 25 \mathrm{IU} / \mathrm{ml}$ (tetanus).

TABLE II -Geometric mean antitoxin concentrations (IU/ml) (95\% confidence intervals) for diphtheria and tetanus

\begin{tabular}{lccc}
\hline Schedule & No of children & Diphtheria & Tetanus \\
\hline $\begin{array}{c}\text { Three doses of triple vaccine } \\
\text { completed at } 8-13 \text { calendar } \\
\text { months }\end{array}$ & 35 & $0.426^{\star}(0.294$ to 0.616$)$ & $0 \cdot 299 \star(0 \cdot 197$ to 0.453$)$ \\
$\begin{array}{c}\text { Three doses of triple vaccine } \\
\text { completed at 6-7 calendar } \\
\text { months }\end{array}$ & 32 & $0.328(0.234$ to 0.458$)$ & $0 \cdot 180^{\star}(0 \cdot 128$ to $0 \cdot 252)$ \\
$\begin{array}{c}\text { Three doses of triple vaccine } \\
\text { completed before } 6 \text { calendar } \\
\text { months }\end{array}$ & 26 & $0.411^{\star}(0.273$ to 0.618$)$ & $0.358(0.231$ to 0.556$)$ \\
$\begin{array}{c}\text { Three doses of triple vaccine } \\
\text { followed by diphtheria/ } \\
\text { tetanus before 2 years of age }\end{array}$ & 36 & $1.325(0.959$ to 1.831$)$ & $1.175(0.865$ to 1.595$)$ \\
\hline
\end{tabular}

${ }^{\star}$ One sample was of insufficient volume to allow accurate measurement and was excluded from the calculation.

TABLE III-Geometric mean antibody titres (95\% confidence intervals) to pertussis antigens

\begin{tabular}{lcccc}
\hline Schedule & $\begin{array}{c}\text { No of } \\
\text { children }\end{array}$ & $\begin{array}{c}\text { Filamentous } \\
\text { haemagglutinin }\end{array}$ & Pertussis toxin & Agglutinogens 2 and 3 \\
\hline $\begin{array}{c}\text { Three doses of triple vaccine completed } \\
\text { at 8-13 calendar months }\end{array}$ & 36 & $1386(848$ to 2266) & $232(167$ to 322) & 3591 (2220 to 5809) \\
$\begin{array}{c}\text { Three doses of triple vaccine completed } \\
\text { at 6-7 calendar months }\end{array}$ & 50 & $1157(757$ to 1768) & $198(142$ to 276) & $2703(1912$ to 3820) \\
$\begin{array}{c}\text { Three doses of triple vaccine completed } \\
\text { before 6 calendar months }\end{array}$ & 37 & $903(500$ to 1631) & $179(130$ to 248) & 2002 (1276 to 3142) \\
$\begin{array}{c}\text { p Values: } \\
\text { Linear regression of logarithmic titres } \\
\text { on age at third dose }\end{array}$ & 0.6 & 0.7 & 0.3 \\
$\begin{array}{c}\text { Student's } t \text { test for difference between } \\
\left.\text { two vaccine groups (denoted }{ }^{\star}\right)\end{array}$ & 0.3 & 0.3 & 0.06 \\
\hline
\end{tabular}

protection $(0.01 \mathrm{IU} / \mathrm{ml}) .^{12}$ Table I shows the distribution of antitoxin concentrations. Children who had low antitoxin concentrations $(<0 \cdot 10 \mathrm{IU} / \mathrm{ml})$ were not clustered in any one group.

Antitoxin concentrations were highest in children who had received the 18 month diphtheria/tetanus booster, significantly higher than those in children who had received three doses of triple vaccine before the age of 6 months without a subsequent booster $(p<0 \cdot 001)$. Among children who did not receive the diphtheria/ tetanus booster, there was no significant difference in antitoxin concentration between those who received their third dose of triple vaccine before 6 months of age compared with those who received this third dose between 8 and 13 months of age (table II). Concentrations of tetanus antitoxin, however, were signifcantly higher in children who received their third dose of triple vaccine before 6 months of age than in those who received it between 6 and 7 months of age $(p=$ $0 \cdot 01$ ).

There was no significant difference in geometric mean titres for each pertussis antibody between children who received their third dose of triple vaccine below age 6 months compared with those receiving this third dose between 8 and 13 months of age. For all three pertussis antibodies there was an increase in the geometric mean titre with age at the third dose of the pertussis vaccine, but no significant trend was found (table III).

\section{Discussion}

This study provides evidence that a 3, 4, 5 month schedule of immunisation with triple vaccine provides adequate protection against diphtheria, tetanus, and whooping cough until the age of the preschool booster. Combined diphtheria/tetanus vaccine is given at $41 / 2-5$ years to ensure protection during school years. Without this booster it is unlikely that any three dose schedule of primary immunisation would provide immunity until school leaving.

It was reassuring that no child had antitoxin concentrations below the minimum protective level of tetanus or diphtheria of $0.01 \mathrm{IU} / \mathrm{ml} .{ }^{12}$ For individual protection against diphtheria, however, a higher level of $0 \cdot 1 \mathrm{IU} /$ $\mathrm{ml}$ is desirable. ${ }^{13}$ The few children with diphtheria antitoxin concentration below $0.1 \mathrm{IU} / \mathrm{ml}$ were not clustered in the accelerated schedule group. Among the children who did not receive a diphtheria/tetanus booster, there was no evidence that those immunised at an accelerated schedule had a significantly lower diphtheria or tetanus antitoxin concentration than those who had received a longer schedule. There is no obvious explanation for the finding that those who received their third dose of triple vaccine before 6 months had a significantly higher tetanus antitoxin concentration than those who received it between 6 and 7 months of age.

As may be expected, the antitoxin concentrations to diphtheria and tetanus were highest in the group who had received the 18 month diphtheria/tetanus booster. However, these children may also be at greater risk of local reactions to a preschool booster. ${ }^{14}$

Double blind trials of pertussis vaccines in the 1940s established a vaccine efficacy of $78 \%$ and found no evidence of waning protection during the two year follow up. ${ }^{15}$ Evidence from studies of combined diphtheria/tetanus/pertussis vaccine after licensing implied that the $3,41 / 2-5$, and $81 / 2-11$ month schedule of immunisation was effective in preventing notified disease for up to 3 years. ${ }^{16-18}$ Although no antibody correlate of protection for whooping cough has been established, the finding that antibody titres to three pertussis antigens were similar in children who completed immunisation before the age of 6 months compared with those who completed it after 8 months of age is reassuring.

Schedules of primary immunisation aim at combining the advantage of providing early protection against whooping cough with adequate longlasting protection against diphtheria and tetanus. In the United Kingdom in the early 1960s an accelerated schedule with three doses of triple vaccine before 6 months of age and a further dose at 18 months was recommended. ${ }^{19}$ Subsequently, concern over low attendance rates for the booster led to the abandonment of the fourth dose and a lengthening of the intervals between the first three doses. This decision was made despite the observation that infants were more likely to attend clinics in the early months of life. ${ }^{8}$ Recent evidence supports the observation that clinic attendance wanes when a child reaches 7 to 8 months of age and that an accelerated schedule may increase the proportion of infants who receive three doses of vaccine. ${ }^{20}$

The schedules evaluated in this study are not the same as the accelerated schedule recently introduced. It is unlikely, however, that a 2, 3, 4 month schedule will be less immunogenic than a $3,4,5$ month schedule. A prospective study of the immediate and long term antibody responses to the new 2, 3, and 4 month schedule is in progress.

We thank Dr Dorothy Cullen, District Medical Officer, Plymouth Health Authority, and the Staff of the authority's Community Child Health Department for their help; Mrs C Andrews and Johanna Watkins for performing the assays; $\mathrm{Dr}$ 
Paddy Farrington for the statistical analysis; and Astra Pharmaceuticals who supplied EMLA lignocaine for surface anaesthesia cream.

1 Department of Health and Social Security. Immunisation against infectious disease. London: HMSO, 1988.

2 Department of Health and Social Security. Immunisation against infectious disease. London: HMSO, 1984

Department of Health. Immunisation against infectious disease. London HMSO, 1990.

4 Halsey N, Galazka A. The efficacy of DPT and oral poliomyelitis immunisation schedules initiated from birth to 12 weeks of age. Bull World Health Organ 1985;63:1151-69.

Di Sant Agnese PA. Combined immunisation against diphtheria, tetanus and pertussis in newborn infants. III. Relationship of age to antibody production. Pediatrics 1949:3:333-44.

6 Miller JJ, Faber $\mathrm{HK}$, Ryan ML, et al. Immunisation against pertussis during the first four months of life. Pediatrics 1949;3:468-78.

7 Barrett CD, McLean IW, Molner JG, et al. Multiple antigen immunisation against poliomyelitis, diphtheria, pertussis and tetanus. An evaluation of antibody responses of infants one day old to seven months of age at start of inoculations. Pediatrics 1962;30:720-36.

8 Ministry of Health. On the state of the public health for the year 1967. London HMSO, 1968.

9 Melville-Smith M, Seagroatt VA, Watkins JT. A comparison of the enzymelinked immunosorbent assay (ELISA) with the toxin neutralisation test in mice as a method for the estimation of tetanus antitoxin in human sera. fournal of Biological Standards 1983;11:137-44.
10 Melville-Smith M, Balfour A. Estimation of Corynebacterium diphtheriae antitoxin: a comparison of the enzyme-linked immunosorbent assay (ELISA) with the toxin neutralisation test. I Med Microbiol 1988;25:279-83.

11 Miller E, Ashworth LAE, Robinson A, Waight PA, Irons LI. Double blind phase II trial in three month-old infants of whole cell pertussis vaccine and phase Il trial in three month-old infants of whole cell pertussis vaceil

12 Smith JWG. Diphtheria and tetanus toxoid. Br Med Bull 1969;25:177-82.

13 World Health Organisation. The control of diphtheria in Europe. Report on a WHO meeting. Copenhagen: WHO, 1990

14 Collier LH, Polakoff S, Mortimer J. Reactions and antibody responses to reinforcing doses of adsorbed and plain tetanus vaccines. Lancet 1979; ; 1364-8.

15 Medical Research Council. The prevention of whooping cough by vaccination BMJ 1951;i:1463-71.

16 Noah N. Attack rates of notified whooping cough in immunised and unimmunised children. BMF 1976;i:357-9.

17 Church MA. Evidence of whooping-cough-vaccine efficacy from the 1978 whooping-cough epidemic in Hertfordshire. Lancet 1979;ii:188-90.

18 Efficacy of pertussis vaccination in England. Report from the PHLS Epidemiological Research Laboratory and 21 area health authorities. BMF 1982;285:357-9.

19 Cannon DA, Cockburn WC, Evans DG, et al, eds. Proceedings of a symposium on immunisation in childhood. Edinburgh and London: E \& S Livingstone, 1960

20 Jones AE, Johns A, Magrath DI, et al. Durability of immunity to diphtheria tetanus and poliomyelitis after a three dose immunisation schedule completed in the first eight months of life. Vaccine 1989;7:300-2.

(Accepted 24 April 1991)

\title{
Relation between nicotine intake and Alzheimer's disease
}

\author{
Cornelia M van Duijn, Albert Hofman
}

Abstract

Objective-To study the association between Alzheimer's disease and nicotine intake through smoking.

Design-Population based case-control study.

Setting-City of Rotterdam and four northern provinces of The Netherlands.

Subjects-198 patients with early onset Alzheimer's disease, 198 controls matched for age and sex, and families of 17 patients in whom Alzheimer's disease was apparently inherited as an autosomal dominant disorder.

Main outcome measures-Age of onset of dementia, relative risk of Alzheimer's disease.

Results -89 of 193 patients with Alzheimer's disease had a history of smoking compared with 102 of 195 controls. Among the patients and controls with a family history of dementia, smoking was significantly less common in those with dementia (40/95 with dementia $v 55 / 96$ controls; relative risk $0 \cdot 35 ; 95 \%$ confidence interval $0 \cdot 16$ to $0 \cdot 78$ ). The risk of Alzheimer's disease decreased with increasing daily number of cigarettes smoked before onset of disease (relative risk 0.3 in those smoking $>21$ /day $v 1$ in non-smokers). In six families in which the disease was apparently inherited as an autosomal dominant disorder, the mean age of onset was $4 \cdot 17$ years later in smoking patients than in non-smoking patients from the same family $(p=0 \cdot 03)$.

Conclusions - These findings suggest an inverse association between smoking and Alzheimer's disease, although smoking cannot be advocated for other health reasons. We speculate that nicotine may have a role in the aetiology of both Alzheimer's disease and Parkinson's disease.

Biostatistics, Erasmus

University Medical School, PO Box 1738, 3000 DR Rotterdam, The

Netherlands

Cornelia M van Duijn, MSC, resident in epidemiology

Albert Hofman, MD

professor of epidemiology

Correspondence to: Ms van Duijn.

BMF 1991;302:1491-4

\section{Introduction}

Alzheimer's disease and Parkinson's disease have been suggested to have a common aetiology..$^{1-3}$ These neurodegenerative disorders share several pathological and neurochemical characteristics. Lewy bodies, one of the hallmarks of Parkinson's disease, are often observed in Alzheimer's disease. ${ }^{2}$ The Alzheimer type pathology is found more often in patients with advanced idiopathic Parkinson's disease than in the general population. In most studies of Parkinson's disease, patients have been observed to smoke less than control subjects. ${ }^{45}$ There is also some evidence that nicotine may improve information processing and attention in patients with Alzheimer's disease, ${ }^{67}$ which suggests that nicotine may have a protective role in Alzheimer's disease. To test this idea we studied smoking habits before the onset of dementia in patients with Alzheimer's disease and controls as part of a genetic and epidemiological study of Alzheimer's disease carried out in The Netherlands.

\section{Subjects and methods}

The study comprised all patients with Alzheimer's disease living in two areas of The Netherlands in whom the disease was diagnosed before the age of 70 and during January 1980 to July 1987. Ascertainment of patients and controls has been described in detail elsewhere. ${ }^{8}$ For this study the diagnosis of Alzheimer's disease was verified independently and all patients fulfilled the criteria for clinical diagnosis of Alzheimer's disease of the National Institute of Neurological and Communicative Disorders and Stroke and the Alzheimer's Disease and Related Disorders Association (NINCDS-ADRDA). ${ }^{9}$ Dementias other than Alzheimer's disease, such as multi-infarct dementia and dementia secondary to alcoholism, depression, metabolic disorders, epilepsy, and other conditions, were excluded. Patients with symptoms of Parkinson's disease before the onset of Alzheimer's disease were also excluded.

The inclusion criteria for patients were: a score on the clinical dementia rating scale of more than $0.5^{10}$; a score on the short portable mental status questionnaire of less than 20 (out of 30$)^{11}$; a score of seven or less on the Hachinski scale ${ }^{12}$; no evidence of abnormalities on computed tomography other than cerebral atrophy; and no evidence of focal dysfunction on electroencephalography. For each patient, a control matched for age (within five years) and sex was selected randomly from the population registry of the municipality where the patient lived.

Based on patients' family history of dementia 